\title{
CONSTRUÇÃO DO APEGO ENTRE O BINÔMIO MÃE E BEBÊ PRÉ-TERMO MEDIADO PELO POSICIONAMENTO CANGURU
}

\author{
BUILDING THE ATTACHMENT BETWEEN MOTHER AND PRETERM BABY DYAD MEDIATED BY KANGAROO \\ POSITION
}

\section{CONSTRUCCIÓN DEL APEGO ENTRE EL BINOMIO MADRE Y BEBÉ PREMATURO POR MEDIO DE LA POSICIÓN CANGURO}

Mariana Quindeler de Salles Abreu ${ }^{1}$, Elysângela Dittz Duarte² ${ }^{2}$ Erika da Silva Dittz ${ }^{3}$

\begin{abstract}
RESUMO
Objetivo: Compreender como as mães vivenciam o posicionamento canguru, na Unidade de Terapia Intensiva Neonatal e apreender a percepção sobre as relações de apego com seus bebês mediadas pelo posicionamento canguru. Método: Caráter qualitativo, descritivo e exploratório. Participaram 9 mães maiores de 18 anos com filhos internados em Unidade de Terapia Intensiva Neonatal com idade gestacional igual ou inferior a 30 semanas, que realizaram o posicionamento canguru, pelo menos duas vezes. Foram excluídas mães que já tiveram filhos internados em Unidade de Terapia Intensiva Neonatal, mães de gemelares, com diagnóstico psiquiátrico e usuárias de psicoativos. A coleta aconteceu, por meio do preenchimento de ficha para obtenção de dados sociodemográficos, entrevista semiestruturada antes e após a realização da posição canguru e o diário da participante. O encerramento da coleta deu-se por saturação e foram analisados, conforme Análise de Conteúdo, na modalidade temática. Resultados: Os dados foram agrupados por temas, emergiram as seguintes categorias: maternidade no contexto da Unidade de Terapia Intensiva Neonatal, Interação mãe-bebê, durante a gestação e após o Canguru, Expectativa e realidade materna, em relação ao Canguru. Conclusão: A posição canguru cumpre sua função conforme norma do Ministério da Saúde, tanto para benefícios clínicos para o bebê como para humanização e aumento do apego mãe-bebê.

Descritores: Método Canguru; Recém-Nascido Prematuro; Apego ao Objeto; Cuidado de Enfermagem.
\end{abstract}

\begin{abstract}
Objective: To understand how mothers experience and perceive the attachment relationship with their babies mediated by the kangaroo position in the Neonatal Intensive Care Unit. Method: This is a qualitative, descriptive, and exploratory study. Nine mothers over 18 years of age with children admitted to the Neonatal Intensive Care Unit with gestational age equal to or less than 30 weeks, and who performed the kangaroo positioning at least twice participated in this study. Mothers who already had children hospitalized in the Neonatal Intensive Care Unit, had twins, had a psychiatric diagnosis and used psychoactive drugs were excluded. Data collection took place by filling out a form to obtain sociodemographic data, by performing semi-structured interviews before and after the kangaroo position, and by analyzing the participant's' diaries. The criterion to end data collectionwas saturation and data were analyzed according to Content Analysis. Results: The data were grouped in themes, and divided into the following categories: Maternity in the context of the Neonatal Intensive Care Unit, Mother-baby interaction during pregnancy and after the Kangaroo, Expectation and maternal reality concerning the Kangaroo. Conclusion: the kangaroo position fulfilled its function according to the Ministry of Health standard, both for clinical benefits for the baby and humanization, and increased mother-baby attachment.
\end{abstract}

Descriptors: Kangaroo-Mother Care Method; Infant, Premature; Object Attachment; Nursing Care.

\section{RESUMEN}

Objetivo: Comprender cómo las madres experimentan la posición canguro en la Unidad de Cuidados Intensivos Neonatales y comprender la percepción de las relaciones de apego con sus bebés por medio de la posición canguro. Método: Cualitativo, descriptivo y exploratorio. Participaron nueve madres mayores de 18 años con hijos ingresados en la Unidad de Cuidados Intensivos Neonatales con edad gestacional igual o menor a 30 semanas, quienes realizaron la posición canguro al menos dos veces. Se excluyeron las madres que ya tenían hijos hospitalizados en la Unidad de Cuidados Intensivos Neonatales, madres con gemelos, con diagnóstico psiquiátrico y consumidoras de psicoactivos. La recogida se realizó mediante las respuestas de un formulario de obtención de datos sociodemográficos, entrevista semiestructurada antes y después de realizar la posición canguro y diario del participante. El cierre de la recolección de datos fue por saturación y se analizaron según Análisis de Contenido, en la modalidad temática. Resultados: Los datos fueron agrupados por temas, surgieron las siguientes categorías: Maternidad en el contexto de la Unidad de Cuidados Intensivos Neonatales, Interacción madre-bebé durante el embarazo y después del Canguro, Expectativa y realidad materna con relación al Canguro. Conclusión: La posición canguro cumple su función según el estándar del Ministerio de Salud, tanto por los beneficios clínicos para el bebé como por la humanización y el aumento del apego madre-bebé.

Descriptores: Método Madre-Canguro; Recién Nacido Prematuro; Apego a Objetos; Cuidado de Enfermería.

${ }^{1}$ Psicóloga. Especialista em Neonatologia pela Faculdade de Ciências Médicas de Minas Gerais. ${ }^{2}$ Pós Doutora em Enfermagem pela School of Nursing/UNC-Chapel Hill. Professor Associado 2 da Escola de Enfermagem da Universidade Federal de Minas Gerais. ${ }^{3}$ Terapeuta Ocupacional. Doutorado em Ciências da Saúde FM/UFMG. Pós-Doutorado em Ciências da Reabilitação pelo EEFFTO/UFMG.

\section{Como citar este artigo:}

Abreu MQS, Duarte EDD, Dittz ES. O processo de construção do apego entre mãe e bebê pré-termo mediado pelo posicionamento canguru. Revista de Enfermagem do Centro-Oeste Mineiro. 2020;10:e3955. [Access http://doi.org/10.19175/recom.v10i0.3955 


\section{INTRODUÇÃO}

A relação da mãe com seu bebê vai muito além de uma interação momentânea, sendo que a qualidade dessa interação pode influenciar, diretamente, no modo como esse indivíduo estabelecerá suas relações com o mundo. Essa relação pode ser entendida como apego, e se constitui em uma busca e preservação da proximidade entre os indivíduos, tão primária e inata como a necessidade de obter alimento ou conforto. A ligação estabelecida do bebê com a chamada figura de apego faz com que, em uma situação de risco, o bebê se vincule a ela para se sentir seguro para explorar o ambiente que a $\operatorname{cerca}^{(1)}$.

A partir das relações com a figura de apego em termos de disponibilidade e responsividade, a criança desenvolverá o chamado modelo operante de self, que guiará o modo como, futuramente, o indivíduo perceberá o mundo, em suas formas de se comportar e relacionamentos pessoais. Um indivíduo provido de segurança, conforto e autonomia, provavelmente, se perceberá como alguém estimado e digno de bons sentimentos ${ }^{(2)}$.

$\mathrm{O}$ nascimento pré-termo e a consequente necessidade de hospitalização do bebê, nas primeiras horas de vida, pode influenciar, negativamente, 0 estabelecimento dessas primeiras relações de apego. $\mathrm{O}$ ambiente da Unidade de Terapia Intensiva Neonatal (UTIN), apesar de necessário, nesse momento de vida do recém-nascido, apresenta uma série de estímulos estressores para o bebê: luminosidade forte, variabilidade de temperatura, alta frequência de procedimentos invasivos e dolorosos, interrupção constante do ciclo de sono. Tais estímulos afetam também a mãe, que pode se sentir insegura diante daquilo que desconhece: tanto o ambiente como a situação clínica de seu bebê ${ }^{(3)}$.

Com seu bebê hospitalizado, a mãe pode se sentir impossibilitada de ofertar os cuidados primários, elementares para o desenvolvimento do bebê e para o estabelecimento da relação de apego. Somam-se a isso componentes psíquicos da mãe que, diante de um bebê diferente do imaginado, durante todo o período gestacional, sente estranhamento. Nesse contexto, a mãe pode ser atingida por sentimentos de inferioridade, ter sua autoestima rebaixada e a capacidade materna questionada, por não ter gerado um bebê saudável ${ }^{(4-5)}$.

Para apoiar o processo de adaptação materna ao cuidado da criança na UTIN, algumas estratégias têm sido adotadas. Dentre elas, temse o Método Canguru (MC), que é definido como um tipo de assistência que preconiza contato pele a pele precoce entre mãe e recém-nascido de baixo peso, de forma progressiva e pelo tempo considerado prazeroso para a díade. $\mathrm{O} M C$, no Brasil, envolve ainda outras estratégias, como manuseio do recém-nascido, atenção às necessidades individuais, acolhimento e participação dos pais nos cuidados ao seu bebê, promoção do apego, acompanhamento ambulatorial pós-alta ${ }^{(6)}$.

Um estudo qualitativo realizado em unidades neonatais da Suíça, Inglaterra e Finlândia aponta a importância do contato físico como tocar, segurar e permanecer em contato pele a pele, entre pais e bebês para que seja possível uma aproximação em nível emocional. $O$ conceito de aproximação em nível emocional estaria ligado à consistência de sentimentos de amor, cuidado, afeição e/ou conexão entre pais e bebê( ${ }^{(4)}$. Em outro estudo, o cuidado canguru afetou, positivamente, o apego materno, especialmente de bebês nascidos a termo, sendo recomendado que o canguru seja incluído nos cuidados de rotina na UTIN, e a importância de prover ambiente e apoio exigido pelas mães para favorecer a interação física e emocional com seus bebês ${ }^{(7)}$. No que se refere aos bebês prematuros, o cuidado canguru teve influências positivas para estabilizar os sintomas fisiológicos, aumentar interação mãebebê, e reduzir o nível de estresse da mãe ${ }^{(8)}$. Adicionado a isso, foi verificada a predominância de sentimentos positivos em mães que realizaram o posicionamento canguru com seus bebês, no ambiente de UTIN, além do aumento do sentimento de confiança, no manuseio do recémnascido, do estímulo ao aleitamento materno e do favorecimento do estabelecimento do apego entre mãe e bebêt ${ }^{(9-10)}$.

Tendo em vista os limites impostos pelo nascimento prematuro e a necessidade de internação do bebê na UTIN para o processo de apego entre mãe e filho, acredita-se que o posicionamento canguru pode ser uma ferramenta a ser utilizada pela enfermagem, para auxiliar no processo de adaptação materna à nova realidade, favorecendo a confiança materna, a criação dos laços de apego e contribuindo para um desenvolvimento psíquico e cognitivo saudável para o bebê.

Acredita-se que a relização de pesquisas sobre as situações que podem favorecer a formação do apego e a promoção da saúde mental 
materna e infantil contribuirão para o conhecimento, nessa área e poderão ser úteis para aportar a prática dos profissionais de enfermagem, no cuidado de recém-nascido e sua família, e qualificando a assistência e repercutindo, positivamente, nos indicadores de saúde.

Essa investigaçao tem como objetivo compreender como as mães vivenciam o posicionamento canguru na Unidade de Terapia Intensiva Neonatal e apreender a percepção sobre as relações de apego com seus bebês mediadas pelo posicionamento canguru.

\section{MÉTODOS}

Trata-se de um estudo de caráter descritivo, exploratório, de abordagem qualitativa como caminho para a investigação da relação mãe e bebê, durante a relação mae canguru, e ainda das subjetividades produzidas, nessa relação e as percepções dos sujeitos sobre ela.

Neste estudo, o referencial adotado foi a Teoria do Apego ${ }^{(11)}$, por reconhecer suas contribuições para compreender o relacionamento do bebê com os pais. De acordo com essa teoria, o apego é um mecanismo básico dos seres humanos e biologicamente programado. $O$ relacionamento entre pais e bebê tem início pelos sinais do bebê que indicam a necessidade de proximidade dos pais como a necessidade de conforto e alimentação. Com o passar do tempo, é desenvolvida a relação afetiva que dará sustentação para as capacidades cognitivas e emocionais da criança. Assim, a teoria do apego tem como pressuposto que as primeiras relações, estabelecidas na infância, irão influenciar o desenvolvimento da criança, ao longo de sua vida.

O estudo foi realizado em uma maternidade de Belo Horizonte que atende, exclusivamente, pelo Sistema Único de Saúde (SUS). O hospital assiste parte da população da cidade de Belo Horizonte e é referência em assistência maternoinfantil para cidades do interior do estado de Minas Gerais. Realiza cerca de 900 partos por mês e conta com 87 leitos obstétricos, 41 leitos de UTI Neonatal, 45 leitos de UCI Neonatal e 12 de outras clínicas ${ }^{(12)}$. A instituição segue as recomendações do Ministério da Saúde no que se refere à assistência ao recém-nascido prematuro e de baixo peso - Método Canguru, que consiste em um modelo de atenção perinatal que visa à qualificação e humanização do cuidado ao recémnascido e família, promovendo a participação desta nos cuidados neonatais. Dentre as intervenções preconizadas pelo método, está a posição canguru, que consiste no ato de manter o bebê em contato pele a pele, apenas usando fraldas, junto ao peito dos pais pelo tempo que for prazeroso e suficiente tanto para os pais como para o bebê. A posição canguru deve ser orientada e assistida por equipe assistencial qualificada ${ }^{(6)}$.

Nas UTIN's da instituição cenário do estudo, os pais possuem livre acesso ao ambiente da UTIN, sendo sua presença, bem como, a realização do posicionamento canguru, encorajadas pela equipe assistencial, visando aos seus benefícios para os pais e o bebê.

Participaram do estudo 9 mães com bebês internados na UTIN. Como critérios de inclusão foram consideradas mães cujos bebês nasceram com idade gestacional igual ou inferior a 30 semanas, com idade igual ou superiror a 18 anos e que tivessem realizado 0 posicionamento canguru, durante internação do bebê, na UTIN por, pelo menos, duas vezes, no momento da entrevista final. Foram excluídas as mães que já tiveram outros filhos que necessitaram de assistência em UTIN, mães de gemelares, mães com diagnóstico de doença psiquiátrica e mães usuárias de álcool e drogas ilícitas.

Para identificar as participantes que preenchiam o critério para inclusão no estudo, foi realizada busca ativa nos prontuários dos bebês internados na UTIN bem como abordagem da equipe de referência para o acompanhamento do bebê na unidade, para identificar se ele tinha condições de realizar o posicionamento canguru. Cabe esclarecer que não houve nenhuma alteração na rotina de cuidado para fins de coleta de dados, sendo o posicionamento canguru realizado no momento indicado pela equipe e conforme decisão da mãe.

Como instrumento de coleta de dados foram utilizados a entrevista semiestruturada ${ }^{(13)} \mathrm{e}$ o diário da participante. A entrevista buscou apreender as expectativas para a vivência do cuidado canguru e as manifestações de apego iniciais e, posteriormente, identificar as implicações dessa vivência no que tange à construção do apego mediada pelo posicionamento canguru. As entrevistas foram realizadas em dois momentos: antes da realização do primeiro posicionamento canguru (entrevista inicial) e, após a mãe ter realizado o posicionamento canguru por, pelo menos, duas vezes (entrevista final) e tiveram como perguntas norteadoras (Quadro 1): 
Quadro 1- Questões norteadoras para entrevista.

\begin{tabular}{|l|}
\hline Entrevista Inicial \\
\hline $\begin{array}{l}\text { Como você se relacionava com seu bebê durante a } \\
\text { gestação? } \\
\text { O que você sentiu no primeiro contato com seu bebê? } \\
\text { O que você espera da realização do posicionamento } \\
\text { canguru? }\end{array}$ \\
\hline Entrevista Final \\
\hline $\begin{array}{l}\text { Como você descreve a experiência do posicionamento } \\
\text { canguru? } \\
\text { Como você percebe sua relação com seu bebê após a } \\
\text { vivência? Houve alguma modificação? } \\
\text { Como é para você ser mãe em um ambiente de UTIN? }\end{array}$ \\
\hline
\end{tabular}

Fonte: Elaborado pelas autoras.

$\mathrm{Na}$ entrevista inicial, além das perguntas norteadoras, também foram obtidas informações sociodemográficas da mãe (nome, idade, estado civil, paridade, escolaridade, profissão) e do filho (nome, idade gestacional e peso ao nascer, Indice de Apgar). As entrevistas realizadas, de acordo com a disponibilidade das participantes e em local reservado. Foram conduzidas pela própria pesquisadora, com domínio da técnica de entrevista. Durante o período de coleta de dados, a pesquisadora que também atuava no serviço de psicologia não realizou atendimentos com as mães que atendiam aos critérios de participação, neste estudo, a fim de evitar qualquer tipo de interferência na produção dos dados. As entrevistas foram gravadas e, posteriormente, transcritas na íntegra pela pesquisadora. O intervalo médio entre as entrevistas inicial e final foi de 28 dias.

Outro instrumento de coleta de dados utilizado foi o diário da participante. Esse instrumento consistiu de um caderno pautado acompanhado de caneta, entregue à mãe após a realização da entrevista inicial. Ela foi orientada, pela pesquisadora, a registrar suas percepções, sentimentos e o que mais considerasse importante sobre a experiência do posicionamento canguru e a relação estabelecida com o recém-nascido, durante o período de internação. Os registros poderiam ser feitos, por meio da escrita, de desenhos, figuras ou outra forma de expressão que a mãe desejasse. Ao encerrar a coleta de dados, o diário permaneceu com a mãe, sendo realizada uma cópia do mesmo pela pesquisadora, após a entrevista final. Dentre as 9 participantes, 4 delas não forneceram o diário para a pesquisadora realizar a cópia.
À medida que foram realizadas as entrevistas, procedeu-se uma pré-análise dos dados para identificar elementos que possibilitassem considerar que tivesse ocorrido a saturação dos dados, tais como: comportamentos de apego e experiência materna em relação ao canguru. Assim, a coleta foi interrompida quando os dados obtidos nas entrevistas já ofereciam elementos para responder aos objetivos do estudo e para contribuir com a produção de conhecimento acerca da temática investigada ${ }^{(13-}$ 14).

Os dados coletados, por meio da entrevista e dos diários foram transcritos, na íntegra, pela pesquisadora e sistematizados de forma a constituir um registro único dos dados coletados de cada participante, contendo entrevista inicial e final e registros do diário. Cabe esclarecer que as participantes utilizaram a escrita como linguagem para se expressarem, sendo realizados alguns desenhos, no sentido de decorar e personalizar o diário, não permitindo reconhecê-los como uma forma de comunicar algo. Após a transcrição, os dados foram analisados, conforme a técnica de análise de conteúdo na modalidade temática ${ }^{(13)}$. Foram identificados os temas centrais que permitiam compreender como se davam as relações de apego entre mãe e filho mediadas pelo posicionamento canguru e o agrupamento dos temas por similaridade possibilitou a constituição das categorias empíricas.

Os dados foram utilizados, em sua totalidade, no processo de categorização. Em seguida, foi realizada uma descrição do resultado obtido na categorização, todavia, para não ficar extenso, foram selecionados alguns relatos para compor o texto. Por fim, foram realizadas inferências sobre os resultados e interpretação dos desfechos obtidos com base na literatura existente acerca da temática ${ }^{(13)}$.

O projeto de pesquisa foi aprovado pelo Comitê de Ética em Pesquisa do Hospital Sofia Feldman, por meio do parecer no 3.359.263 e a coleta de dados apenas teve inicio, ao ser obtida a assinatura do Termo de Consentimento Livre e Esclarecido (TCLE). Todas as mães que foram convidadas pela pesquisadora aceitaram participar do estudo. Para assegurar o anonimato das participantes, foi adotada a letra " $\mathrm{M}$ " seguida da numeração correspondente à ordem de realização da entrevista ( $M 1, M, 2, M 3, \ldots)$. Foi ainda acrescido código que permitisse identificar a fonte do dado, assim, para entrevista inicial 
usou-se El; entrevista final EF e diário de campo DC.

\section{RESULTADOS E DISCUSSÃO}

Tomando como referencial a Teoria do Apego, buscou-se identificar os elementos que pudessem contribuir para as relações de apego entre mãe e filho, no contexto do cuidado canguru. Tais elementos estavam relacionados ao ambiente, aos aspectos do bebê e aos sentimentos e expectativas maternas. Assim, foram estruturadas três categorias empíricas: 1) Maternidade no contexto da Unidade de Terapia Intensiva Neonatal, 2) Interação mãe-bebê, durante a gestação e após o Canguru, 3). Expectativa e realidade materna em relação ao Canguru. A seguir, apresentaremos as categorias empíricas seguidas do diálogo estabelecido com a literatura disponível sobre a temática em estudo.

\section{Maternidade no contexto da UTIN}

Nessa categoria, as participantes expressaram que a vivência tanto da prematuridade quanto da necessidade de internação do bebê, em UTIN, é algo novo, pois não esperavam circular pelo espaço de uma unidade de terapia intensiva. A imprevisibilidade foi expressa pelas mães, em relação ao quadro clínico da criança que pode piorar a qualquer momento, gerando insegurança e receio.

"Para mim, no primeiro momento eu fiquei bem abalada. Nunca tinha entrado em uma UTI na vida, nem de adulto nem de criança" (M1, EF).

"No começo foi muito difícil, porque eu nunca imaginaria que eu ia passar por isso, ver ela lá dentro, cheia de aparelhos, a gente não entente muito dos aparelhos..." (M2, EF).

"É difícil porque a gente não sabe se ele vai melhorar, se ele vai piorar. A gente fica meio insegura, assim. Em relação à UTI, né?" (M4, EF).

Adicionado a isso as mães relataram também uma dificuldade, em alguns momentos, de sentirem-se mães dos próprios bebês, em razão da impossibilidade de realizar os cuidados.

"É muito bom. Mas eu acho que ainda, mãe, mãe, mãe, eu acho que é só quando eu tiver na prática, lá no dia a dia, eu tendo que fazer tudo. Até então, está tranquilo, aparentemente tudo tranquilo. Eu fico observando, já pra pegar algumas coisas, a forma de trocar fralda, essas coisinhas assim. Mas se tivesse em casa era bem melhor" (M3, EF).

"Ah, é diferente, né? Porque você vai lá e fica só olhando, não pode pegar toda hora, não pode entrar toda hora. Quando pode entrar tem procedimento e a gente fica querendo saber se é no nosso filho, querendo saber qual que é. É diferente, é difícil as vezes"(M5, EF).

Com o passar do tempo, as mães demonstram um entendimento sobre a UTIN e o cuidado ali prestado e descoberta de possibilidades para praticar a maternidade. Esse processo favorece $o$ aprendizado e parece contribuir para a mãe sentir-se mais segura para realizar o cuidado e experimentar outras formas de aproximação.

"[...] Mas agora eu fico bem mais tranquila, eu entendo que lá, que, no momento, ela precisa daquilo lá. Então eu fico super tranquila" (M1, EF).

"[...] agora que eu perdi o receio, já consigo colocar a mão, colocar a mão na incubadora, essas coisas" (M3, EI).

"[...] mas eu já aprendi bastante coisa, a dieta, agora eu já conecto a dieta, sei arrumar ele pro tubo ficar melhor, essas coisinhas" (M6, EF).

"É um amor incondicional, no começo é apenas um cuidado, mas depois que o vê sorrir pra você, chorar quando você vai embora, quando está com fome, ou sente o respirar dele em você, todos os problemas se vão! O verdadeiro fica" (M4, DC).

\section{Interação mãe-bebê, durante a gestação e com o posicionamento Canguru.}

Foi possível extrair dos relatos das entrevistadas, que a interação com seus bebês, durante a gestação ocorria, por meio da fala e carícias realizadas na barriga. Os movimentos fetais intraútero funcionavam como uma resposta à comunicação iniciada por elas, e servia como estímulo para a manutenção da interação.

"Eu conversava todos os dias, passava muito a mão na barriga porque ela era bem... mexia bastante. Era uma relação bacana" (M1, EI)"

"Depois de 25 semanas ele começou a chutar, então toda vez que ele estava estressado, nervoso, ele chutava, e aí eu tentava acalmar ele fazendo carinho. Funcionava demais, ele ficava bem quietinho, bem tranquilo" (M4, El).

Algumas mães expuseram que o tempo que tiveram para manter contato com o bebê, durante a gestação foi rápido, devido ao nascimento prematuro.

“Olha, foi tão rápido, mas tão rápido, que quando eu vi ela já estava no meu braço" (M7, EI).

"Ah, eu não tinha muito hábito de conversar com ela não. Para mim era tudo muito novo, então 
eu achava meio esquisito, eu nunca fui muito de conversar não. Quando eu comecei a criar aquilo, aquela coisa de querer conversar e tudo mais, aí já foi tarde, ela nasceu" (M3, EI).

A ambivalência de sentimentos vivenciado por uma das mães fica evidente, diante da descoberta da gravidez e do processo de aceitação da gestação não desejada.

"Eu ficava cantando para ele, e até os três primeiros meses tinha vez que eu rejeitava, arrependia de ter engravidado. E depois eu chorava, porque eu arrependia de ter falado que eu me arrependia, porque ele não tinha culpa de nada" (M6, EI).

Realizar o canguru possibilitou dar continuidade a uma relação que teve início na gestação e foi interrompida pelo nascimento prematuro. Além disso, favoreceu a aproximação entre mãe e filho, sendo que todas as mães participantes do estudo sentiram reciprocidade por parte do bebê, que era expressa por meio da capacidade dele reconhecer a presença da materna:

“Percebo que o método canguru é ter a oportunidade de estar perto do filho e passar para ele uma segurança que ele tinha na barriga, e a mãe sentir através de ter esse contato oportuno com seu filho" (M6, DC).

"Ah, mudou, ele ficou mais pertinho, pegou mais peso" (M8, EF).

"Ela presta mais atenção, depois que eu peguei ela, ela presta mais atenção. Parece que me sentiu mais presente" (M7, EF).

"Parece que ele me reconhece mais. Eu acho que, quando eu chego, ele me vê e consegue me reconhecer bem mais" (M5, EF).

Realizar o canguru foi, para a maioria das mães, o momento que elas puderam estar próximas, fisicamente, dos seus bebês é considerado o primeiro encontro com ele. Foi também a oportunidade para as mães transmitirem segurança e otimismo para o bebê.

"Quando peguei minha filha na primeira vez, onde ela olhou para mim, meu mundo parou ali naquele momento. Foi a melhor coisa que eu fiz foi aceitar fazer o MC, virar um "canguru" e pegar minha "filhotinha" e segurá-la no meu braço e mostrar para ela que eu estava ali e ela precisava viver porque tinha um amor muito grande a esperando fora daquela incubadora" (M2, DC).

O contato entre mãe e bebê oportunizado pelo Canguru contribuiu para que as mães se aproximassem e interagissem com seus bebês.
Essa proximidade favorece o aprendizado das mães sobre o comportamento e desenvolvimento do bebê e contribui para que se sintam fortalecidas no seu papel materno

"[...] depois eu fiz canguru várias vezes e ainda faço, percebi que o canguru ajuda meu bebê a ficar mais calmo ele me reconhece bem mais também e tem ajudado ele a ganhar peso mais rápido" (M5, DC).

"Eu acho que quando eu chego, assim, que ele tá nervoso, eu ponho a mão nele e ele acalma, ele fica mais quietinho" (M9, EF).

"Para mim, agora eu estou mais apegada ainda a ele, e eu me sinto mais a vontade de cuidar dele, tipo, eu perdi o medo" (M6, EF).

\section{Expectativa e realidade materna em relação ao Canguru}

Os dados evidenciam o ganho de peso como o principal benefício clínico atribuído pelas mães em relação ao Canguru. A evolução clínica do bebê e expectativa de alta são os primeiros motivadores para a realização do Canguru.

"Ah, não sei, não sei explicar. O que eu espero? Ah, que ele pegue peso, que ele saia logo dali. É isso que eu espero" (M8, El).

"Espero que ela ganhe peso rápido, que ela vá pra casa rápido ficar comigo" (M7, El).

"Ah, que ele engorde bastante pra gente ir embora rapidinho!" (M9, E1).

Houveram também relatos que evidenciaram a expectativa materna de proximidade com o bebê que se encontrava restrita, em razão da internação na UTIN. Essa proximidade é também a oportunidade de retomar um contato que havia se iniciado durante a gestação.

"[...] que a gente tenha contato, porque quase não tem, ele lá dentro e eu aqui, a gente quase não tem contato de mãe e filho nenhum" (M5, EI).

"Eu espero que ele possa me sentir de novo, porque o bebê prematuro eu acho que as vezes se sente um pouco sozinho, sem a gente. Porque a gente não pode estar 24 horas lá do lado da incubadora, então eu acho que ele vai se sentir abrigado de novo. Acho que é isso" (M4, EI).

Por outro lado, vieram à tona a insegurança e o sentimento de medo dessas mães, em relação ao contato com seus bebês, por considerá-los frágeis, em razão da prematuridade e às condições clínicas. O cuidado canguru surge, nesse contexto, como uma possibilidade para o aumento da 
segurança dessas mães em relação aos próprios filhos.

"Bom antes do canguru, eu sentia medo, insegurança. Não estava sabendo lidar com tudo que estava acontecendo, pois não tinha sentido o meu filho como imaginava que seria ao nascer" (M6, DC).

"Ah, perder o medo, né? Perder o medo acho que vai ajudar demais. Perder o medo, ter mais segurança, ir pegando ela" (M3, EI).

"Demorei pouco menos de uma semana para colocar as mãos dentro da incubadora pois tinha medo de passar algum tipo de infecção pra ele ou algo do tipo. Depois mais uma semana para fazer o canguru, achava ele tão frágil” (M4, DC).

Para as mães, a primeira vez que realizaram o Canguru não foi tranquilo e demandou certo esforço da mãe e do bebê para se ajustarem um ao outro. As mães sentiram-se receosas de segurar os bebês e estes, por sua vez, reagiram com comportamento defensivo e de estresse, chorando e se agitando no colo da mãe. A distância entre a expectativa e a realidade foi sendo reduzida, à medida que se repetia a realização do Canguru.

“Na primeira vez eu tive um pouco de dificuldade, porque eu fiquei com receio. Estava parecendo que estava colocando um gato em cima de mim, tentando escalar. Aí na segunda vez já foi tranquilo, da terceira foi tranquilo, aí agora eu quero pegar todo dia" (M3, EF).

"Ele me estranhou e ficou tão nervosos que ARRANCOU o CPAP inteiro; Ele chorou MUITO até achar uma posição agradável; Ele respirou apenas com o oxigênio perto do nariz, então tinha alguns picos e quedas; Eu fiquei tão tensa, achando que ele me rejeitaria que fiquei com dores nas costas" (M4, DC).

Foram reconhecidos pelas mães os benefícios clínicos que as motivaram a realizar o Canguru, como ganho de peso e estímulo ao aleitamento materno.

"Mas foi muito gostoso, e tá sendo muito bom pra ela, pra mim... Meu leite aumentou, depois do Canguru, ela tá ganhando peso bem..." (M1, EF).

"Depois que comecei a fazer o Canguru vi muitas mudanças em minha bebê: ganho de peso; reconhece minha voz; sente cheirinho do leite e fica querendo mamar" (M2, DC).

No que diz respeito aos benefícios emocionais, os relatos demonstraram o fortalecimento do apego das mães com seus bebês, além do aumento da segurança tanto na própria condição materna quanto em sua capacidade de cuidar de seus filhos, mesmo internados em uma unidade de terapia intensiva.

"Foi muito bom para mim que estava insegura, eu até tinha comentado isso, então para mim foi ótimo, já quero pegar ela sempre. Ajudou demais na insegurança" (M3, EF).

"Após uns 20 minutos de colo, ele havia se acalmado, nossos corpos eram um só novamente, trocamos calor e todo o medo do "desconhecido" havia passado. Éramos só eu e meu bebê" (M4, DC).

Os achados do estudo vão ao encontro da literatura, na medida em que são reiterados sentimentos maternos de insegurança, medo e impotência frente à realidade da internação do bebê na UTIN e sua prematuridade ${ }^{(15)}$. No caso do presente estudo, a prematuridade em questão é extrema, o que pode potencializar os riscos aos quais os bebês estão submetidos e contribui para aumentar os sentimentos maternos já citados.

Foi evidenciada uma resiliência das mães, no que tange à recuperação dos próprios filhos. As mulheres passam a estar mais atentas às informações que lhes são transmitidas pela equipe $e$ aos procedimentos realizados rotineiramente. Esse achado é reforçado por estudo que indica que vivência diária com o bebê pré-termo na UTIN contribui para a mãe desenvolver a autoconfiança e a reestruturação do papel materno além de ser importante para o preparo das mães para o cuidado no domicílio ${ }^{(16)}$. Destaca-se que o conhecimento adquirido pelas mães, no ambiente hospitalar, propicia o reconhecimento, compreensão e resposta aos sinais comportamentais do bebê, percepções que as auxiliam no cuidado tanto durante a internação quanto no pós-alta hospitalar ${ }^{(17)}$. Esse achado é relevante no que tange a teoria do apego, uma vez que foram identificados como fatores que podem interferir na ativação do sistema de comportamento do apego os relacionados às condições físicas e temperamentais da criança, e os relacionados às condições do ambiente ${ }^{(18)}$.

Fica evidente a inevitabilidade da vivência dos sentimentos negativos frente ao desafio de ter um bebê prematuro extremo internado em uma UTIN. É recomendado que os profissionais encarregados da assistência, especialmente os da enfermagem que permanecem, continuamente, junto ao binômio mãe-bebê, tenham um entendimento acerca do processo psíquico em questão, possibilitando-lhes desenvolver ações no 
intuito de minimizar o impacto negativo característico da situação.

A dinâmica da formação do apego entre mãe e bebê, ainda na gestação, foi impulsionada, principalmente, pela fala e mantida, na medida em que a mãe sente a reciprocidade de seu filho, por meio dos movimentos fetais. A importância dessa interação é reforçada pelo entendimento que a ligação materno-fetal é um precedente significativo de ligação pós-natal entre mãe e bebê ${ }^{(19)}$. A manutenção do contato oportunizada, pelo posicionamento canguru mostrou-se uma oportunidade de continuidade desse primeiro contato, interrompido pelo nascimento prematuro, além de serem benéficas para o bebê, uma vez que a exposição a sons maternos entre a 26a e 33a semana, favorece a maior estabilidade fisiológica e clínica dos bebês pré-termo ${ }^{(20)}$. Pelo exposto, pode-se considerar que a equipe de enfermagem tem um papel significativo, no sentido de favorecer o apego entre mãe e bebê, por meio da criação de oportunidades para que a mãe esteja junto desse o mais precocemente possível.

Ainda sobre o posicionamento canguru, percebe-se que, num primeiro momento, as mães participantes do estudo foram motivadas a realizá-lo pelos benefícios clínicos do método no que se refere ao crescimento e desenvolvimento do bebê. Contudo, ao experienciarem o método, perceberam os resultados condizentes com a aproximação e fortalecimento do sentimento de apego, cuidado e segurança maternas. $O$ bebê carece de toque materno e outros estímulos, uma vez que está exposto a situações que causam estresse, no ambiente da UTIN e que comprometem o seu desenvolvimento físico, psicológico e cognitivo ${ }^{(7)}$. Em relação às mães, os resultados mostraram que, por vezes, necessitaram reajustar suas expectativas sobre como seria a experiência do primeiro contato com o filho, ajuste que é fundamental no processo de luto vivenciado pela mãe ao se deparar com um bebê diferente do previamente idealizado durante a gestação. Nesse contexto, o toque e o contato pele a pele podem propiciar a constituição da criança como pessoa e contribuir para o apego entre ela e seus pais ${ }^{(21)}$.

Percebeu-se que as mães demonstram já possuir conhecimento prévio acerca dos benefícios do Canguru para o bebê. Tal achado pode estar relacionado à livre presença da mãe na UTIN, às interações que estabelece com a equipe assistencial e a realização de grupos de orientação pela equipe multiprofissional, além da troca de experiências constante com outras mães na mesma situação. Adicionado a isso, oferecer informações às mães sobre as rotinas de cuidado pode reduzir as repercussões emocionais decorrentes da internação do bebê na UTIN ${ }^{(22)}$. Os dados reforçam, dessa forma, os benefícios do posicionamento canguru para a saúde mental materna, na medida em que reduz o estresse característico da vivência da internação e da prematuridade extrema, além de fortalecer sentimentos de confiança e segurança em si mesmas. $\mathrm{O}$ investimento em práticas educativas pela equipe de enfermagem, visando a favorecer o aprendizado materno, pode contribuir para o aumento da segurança materna para os cuidados do bebê e, consequentemente, a redução do estresse materno decorrente do nascimento prematuro e da necessidade de hospitalização.

As limitações observadas, no estudo, dizem respeito ao fato de que, no cenário de estudo, um conjunto de ações são realizadas para favorecer a aproximação entre mãe e filho tais como: o livre acesso à UTIN, condições de permanência na instituição e acompanhamento pela equipe multiprofissional, durante todo o período de internação do bebê na UTIN. Portanto, os resultados obtidos, nesta investigação, podem não ser resultantes, exclusivamente, da posição canguru.

\section{CONSIDERAÇÕES FINAIS}

Foi possível evidenciar sentimentos iniciais, predominantemente, negativos frente à internação e prematuridade de seus filhos, e a inevitabilidade dos sentimentos em questão, cabendo à equipe de saúde compreender a vivência e minimizar os danos, na medida do possível. Percebeu-se um fortalecimento psíquico-materno, motivado pela presença constante na unidade intensiva e pela realização do Posicionamento Canguru, além do fortalecimento significativo das relações de apego das mães com seus bebês e dos benefícios clínicos já comprovados do método.

O estudo reafirma achados da literatura acerca das contribuições da posição Canguru. fortalecendo a adoção dessa prática, no contexto do cuidado ao recém-nascido prematuro. Portanto, o posicionamento canguru cumpre sua função, conforme o preconizado na norma do Ministério da Saúde, tanto no que tange a benefícios clínicos para o bebê quanto no concernente à humanização do cuidado e 
aumento do apego entre mãe-bebê. Recomendase, assim, que os profissionais da enfermagem favoreçam a realização do posicionamento Canguru o mais brevemente possível como um importante recurso para minimizar os danos causados pela separação precoce do binômio mãe e filho.

\section{REFERÊNCIAS}

1- Bowlby J. Apego e perda: Separação. São Paulo: Martins Fontes; 1984.

2- Mendes LST, Rocha NS. Teoria do apego: Conceitos básicos e implicaçoes para a psicoterapia de orientação analítica. Rev Bras Psicoter. 2016 [citado em 18 ago. 2020]; 18(3):1$15 . \quad$ Acesso em: http://rbp.celg.org.br/detalhe artigo.asp?id=209 3- Baseggio DB, Dias MPS, Brusque SR, Donelli TMS, Mendes $P$. Vivências de mães e bebês prematuros durante a internação neonatal. Temas Psicol. 2017;25(1):153-67. DOI: 10.9788/TP2017.1-10

4- Flacking R, Thomson G, Axelin A. Pathways to emotional closeness in neonatal units: A crossnational qualitative study. BMC Pregnancy Childbirth. 2016;16(1):170. DOI: 10.1186/s12884016-0955-3

5- Brazelton TB, Cramer BG. As primeiras relações. Porto Alegre: Artes Médicas; 1992.

6- Ministério da Saúde (BR). Atenção humanizada ao recém-nascido de baixo peso: Método Canguru. Brasília: Ministério da Saúde; 2017.

7- Kurt FY, Kucukoglu S, Ozdemir AA, Ozcan Z. The effect of kangaroo care on maternal attachment in preterm infants. Niger J Clin Pract. 2020;23(1):2632. DOI: 10.4103/njcp.njcp 1431

8- Cho ES, Kim SJ, Kwon MS, Cho H, Kim EH, Jun $E M$, et al. The effects of kangaroo care in the neonatal intensive care unit on the physiological functions of preterm infants, Maternal-Infant Attachment, and Maternal Stress. J Pediatr Nurs. 2016;31(4):430-8.

DOI:

10.4103/njcp.njcp $143 \quad 18$

9- Araujo AMG, Melo LS, Souza MEDCA, Freitas MMSM, Lima MGL, Lessa RO. A experiência do método canguru vivenciada pelas mães em uma maternidade pública de Maceió/AL. Rev Iberoam Educ Invest Enferm. 2016 [citado em 18 ago 2020]; 6(3):19-29. Acesso em: https://www.enfermeria21.com/revistas/aladefe Larticulo/210/

10- Heck G, Lucca H, Costa R, Junges C, Santos S, Borck M. Compreensão do sentimento materno na vivência no Método Canguru. Rev Enferm
UFSM 2016;6(1):71-83.

DOI:

$10.5902 / 2179769218083$

11- Bowlby J. Uma base segura: Aplicações clínicas da teoria do apego. Porto Alegre: Artes Médicas; 1989.

12- Hospital Sofia Feldman. Neonatologia. Belo Horizonte: HSF; 2020 [citado em 18 ago 2020]. Acesso: https://www.sofiafeldman.org.br/porque-o-sofia/neonatologia

13- Minayo MCS. O desafio do conhecimento: Pesquisa qualitativa em saúde. 13a ed. São Paulo: Hucitec; 2013.

14- Huberman AM, Miles M, Saldana J. Qualitative data analysis: A methods sourcebook. The United States of America: SAGE publications; 2020.

15- Frigo J, Zocche D, Palavro G, Turatti L, Neves $E$, Schaefer T. Percepções de pais de recémnascidos prematuros em unidade de terapia intensiva neonatal. Rev Enferm UFSM 2015;5(1):58-68. DOI: 10.5902/2179769212900

16- Veronez $M$, Borghesan NAB, Corrêa DAM, Higarashi IH. Vivência de mães de bebês prematuros do nascimento a alta: Notas de diários de campo. Rev Gaúcha Enferm. 2017;38(2):e60911. DOI: 10.1590/19831447.2017.02.60911

17- Dittz ES, Alves CRL, Duarte ED, Magalhães LC. Contribution of the Newborn Behavioral Observations (NBO) for the maternal care of preterm neonates. J Hum Growth Dev. 2017;27(3):262-71. DOI: 10.7322/jhgd.125522

18- Bowlby J. Apego e perda: Apego: A natureza do vínculo. São Paulo: Martins Fontes; 1990.

19- Roncallo CP, Miguel MS, Freijo EA. Vínculo maternofetal: Implicaciones em el desarrollo psicológico y propuesta de intervención en atención temprana. Escritos Psicologia 2015;8(2):14-23. DOI: 10.5231/psy.writ.2015.0706

20- Portugal CMGSL, Sá LO, Areias MHFGP. Os efeitos cardiorrespiratórios dos sons maternos no recém-nascido das 26 às 33 semanas de idade gestacional. Rev Enf Ref. 2017;4(12):55-64. DOI: 10.12707/RIV16075

21- Carvalho LS, Pereira CMC. As reações psicológicas dos pais frente à hospitalização do bebê prematuro na UTI neonatal. Rev SBPH 2017 [citado em 19 dez 2020]; 20(2):101-22. Acesso em: http://pepsic.bvsalud.org/scielo.php?script=sci a rttext\&pid=S1516-08582017000200007\&lng=pt

22- Fraga E, Dittz ES, Machado LG. A construção da co-ocupação materna na Unidade de Terapia Intensiva Neonatal. Cad Bras Ter Ocup. 
2019;27(1):92-104. DOI: $\quad \underline{10.4322 / 2526-}$

$\underline{\text { 8910.ctoao1125 }}$

Nota: Não houve financiamento por agência de fomento.

Recebido em: 20/08/2020

Aprovado em: 21/12/2020

Endereço de correspondência:

Erika da Silva Dittz

Rua Castelo de Setúbal, 540/502 - Bairro Castelo

Cep 31330090 Belo Horizonte, Minas Gerais

erikadittz@gmail.com 31997246408 